02

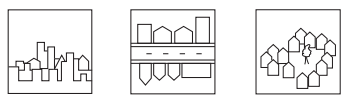

\title{
A CREATIVE “NANOTOWN”
}

\section{Framing Sustainable Development Scenarios with Local People in Calabria}

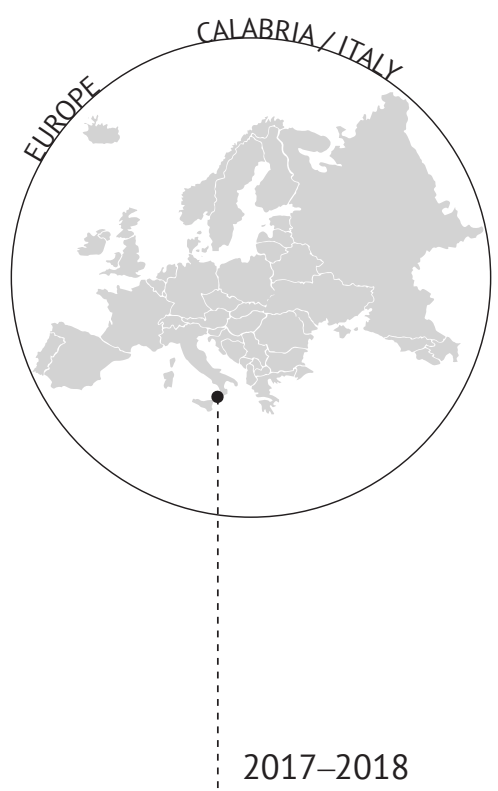

\begin{tabular}{rll} 
Organisations + Collaborators & Authors \\
The University of Westminster & Giulio Verdini \\
\cline { 2 - 2 } The London School of Economics & Urban Development \\
& Olivia Bina \\
& Geography \\
Università Mediterranea di & Pilar Maria Guerrieri \\
Reggio Calabria & Architecture \\
Università della Calabria & Alan Mace \\
& ILAUD & Christian Nolf \\
& Urban design \\
Citizens of Gagliato & Etra Connie Occhialini \\
& Urban design \\
ANTREPID & Anna Paola Pola \\
& Urban planning \\
Academy of Nanosciences & Paola Raffa \\
& Architecture \\
&
\end{tabular}

\section{Introduction}

During a two-year research programme from 2016 to 2018, scholars and students from different disciplinary backgrounds engaged with the local community of the town of Gagliato in Calabria, Italy, to co-produce future scenarios of local development. The aim was to enable a transition towards sustainability for a town affected by economic and demographic decline, like many other rural areas of southern Italy, but also be the protagonist of a promising annual summer science festival which had contributed to raising some expectations of change.

The research has been designed to enable transdisciplinary knowledge production in the urban field that could matter for the local community and would ultimately produce a real, positive impact on people's lives. Despite its broad premises to test innovative learning practices with participating students for an ideal future academia, its concrete outcomes have been deeply ingrained in the local community, becoming part of their discussions of daily life and even informing their political agenda.

FIGURE II.2.1 A view of the Ionian Sea coastline from Gagliato. Photo by Giulio Verdini. 
Therefore, the aim of this chapter will be to reflect on the enabling conditions that have made possible the implementation of the co-design and co-production process from various perspectives; in particular, the role of academia in facilitating this process. However, this would not suffice to explain its successful results, which are instead inextricably intertwined with the role played by the Academy of Nanosciences of Gagliato. This non-profit organisation was founded in 2009 to support an annual gathering of international experts, and, since then, it has contributed to create an "atmosphere of change" within the municipality, generating a fertile terrain to test civic engagement tools.

The chapter intends to be both scientifically sound and narratively engaging, given the richness of the work done in Gagliato as experienced by the authors. As a matter of fact, besides the research done remotely, the authors gathered in Gagliato in July 2017 for a one-week participatory design workshop, getting to know the local context, talking with local people, materialising the focus groups implemented on site in future visions of sustainable development. The following sections will introduce a theoretical section regarding current debates on transdisciplinary research and the reason why Gagliato has been considered a suitable case to test it. Later on, a brief account of this experience is reported, particularly focusing on the enablers and barriers encountered in the process. This section will be backed by an ex-post evaluation carried out by the scholars involved. The conclusion will distil some learning from this process.

\section{Transdisciplinary Research in Gagliato: A Theoretical Framework}

The discussion on inter- and transdisciplinarity in urban studies is not new. Yet, it seems to revolve around the long-lasting dilemma that, despite a persistent rhetoric about its necessity, results have been quite disappointing (Petts, Owens, \& Bulkeley, 2008). The problem is typical of any kind of emerging fields of studies where, in the absence of a certain critical mass, scholars are isolated in a dangerous state of "intellectual marginality" (Aagaard \& Siune, 2002). The question in urban studies, and particularly in urban planning, has been quite serious. The demonisation and, in part, the failure of comprehensive planning, as conceived during the welfare state period, determined at least from the seventies a gradual withdrawal of any ambitions to solve, or even understand, urban problems holistically. This has left space for a plethora of approaches mostly involved in dealing with partial urban problems, from the rejection of "grand utopias" and the advocacy for the "collage city" (Rowe \& Koetter, 1978) to the overemphasis of architectural design as (the only) solution for cities (Dyckhoff, 2016).

In recent years, a new urban question has arisen, especially due to the dangerous combination of massive urbanisation in the Global South and profound urban restructuring in the West, with increasing and sometimes dramatic social and environmental costs (Merryfield, 2014). This has reopened the terms of the debate. Particularly intense has been the discussion stimulated within the social science on its role in tackling the problems of the urban age and in generating knowledge that could help to address its future sustainability (World Social Science, 2014). To put it briefly, the issue of improved governance, including wider participatory urban politics, inclusion and co-production of urban knowledge has gained momentum and is now increasingly regarded as a precondition for achieving sustainable urban futures (Elmqvist et al., 2018). It is in this context that transdisciplinarity has emerged, or re-emerged in different forms, given the fortune of participatory urban practices in the sixties. However, the intensification of academic research and practices of transdisciplinarity, as also witnessed in this volume, faces some underlying problems, which occurred also in the case object of this chapter. As has been recently nicely summarised, "transdisciplinary co-production 
is inherently complex, time consuming and often unpredictable in terms of outcomes, and these challenges are intensified when it is undertaken comparatively" (Simon, Palmer, Riise, Smit, \& Valencia, 2018). Moreover, as this edited book suggests, such challenges might lie in the context, the process or the competences employed in inter- and transdisciplinary urban projects.

These points were discussed in an INTREPID workshop held in London in March 2017 from the point of view of the role that academia should play to facilitate a process of transdisciplinary knowledge production (Bina, Verdini, Inch, Varanda, Guevara \& Chiles, 2017). It was in that specific context that the idea of "porous" and "open" universities (to the wider society) was put forward, endorsing the practice of the participatory design workshop (or scenario workshop, here used without distinction) as a suitable method to bridge the gap between theory and practice and between academics and the outside world. Far from being just an ordinary design studio, which has become a common practice of architecture and urban design courses, but often resulting in abstract simulations of reality, a participatory design studio has the advantage of co-producing the agenda of work (the "brief" as traditionally addressed) with a community, and has the ambition to face, and possibly solve, problems that matter to people.

It is for this reason that the case of Gagliato was suggested. Gagliato had been previously included in a research study on "Creative small settlements" (Verdini \& Ceccarelli, 2017) carried out in 2015-2017 by several institutes across the world to feed the United Nations Educational, Scientific and Cultural Organization global report "Culture: Urban future" presented at the UN-HABITAT III conference in Quito 2016 (United Nations Educational, Scientific and Cultural Organization, 2016). The town was the protagonist of an interesting experience of community engagement linked to various opportunities of local development, as will be explained in the next section, and therefore was "ready" to advance along this path. Gagliato was also quite suitable for another practical reason: being a very small rural town, it was a microcosm where the dynamics and demands of different social groups could be relatively more easily understood, although the complexity of local stakeholders was still high. It is also fair to add that the community, including their political leaders, was also willing (if not excited) to embark in an academic experiment.

In terms of pedagogical process, students and scholars could simultaneously reflect on ideas and ways to implement them. They were exposed for a limited but intense period of time to the local community, and this determined a condition for wider accountability of their actions (Verdini, Bina, \& Cioboata, 2018). It is an aspect that Hannah Arendt has addressed in the theory of social action in the attempt to reconcile the contemplative and active life (Arendt, 1958). It promotes an idea of knowledge by making, within the dimension of the public sphere, to achieve meaningful social outcomes. In the Italian context, this was widely experimented in the pioneer educational activities of the International Laboratory of Architecture and Urban Design, often materialised in famous experiences of local participations such as the ones in Rimini and Terni (De Carlo, 2013). It is not the case that the International Laboratory of Architecture and Urban Design was invited to participate in the Gagliato workshop.

In terms of pedagogical outcomes, the workshop followed the recommendations of the agenda put forward by the United Nations Educational, Scientific and Cultural Organization in "Education for sustainable development," which promotes learner-centred approaches, action-oriented learning and transformative knowledge (United Nations Educational, Scientific and Cultural Organization, 2017). These outcomes will be reported in the next section.

In terms of impact and knowledge sharing, which is ultimately the most meaningful indicator by which one can evaluate the effective sustainability achieved by any action (academic or not), the 
local community has been empowered and has started a process of transition towards sustainability. This part is the most delicate and difficult to assess, as it will be possible to understand it entirely only in the long run. Nevertheless, the chapter will also provide evidence of some preliminary and promising results achieved.

\section{The Experience of Gagliato ${ }^{1}$}

Gagliato is a hilly town located in the province of Catanzaro in Calabria, overlooking the Ionian Sea. Its economy is traditionally rural, primarily based on agriculture, sheep farming and artisanal manufacturing on a family scale. It has witnessed a steady population decline since the 1950s: from 1,768 people in 1951, the town shrank to 524 in the last census in $2011(-71 \%)$ A recent survey indicates an even smaller community of 484 inhabitants (2016), of which $16 \%$ are over the age of 60 and only $3.5 \%$ are under the age of ten. The unemployment rate is rather high, affecting $18 \%$ of the active population. While overall the economy has shifted to public-sector services in the last few years, local enterprises (mostly family-run and small-scale) persist. They belong to the construction sector, with a minimum presence of retail and professional services, and to the agriculture sector, in some cases with emerging niche produce such as oregano, honey and cheese.

The town also benefits indirectly from its proximity to the coast, so that many vacant houses can be rented out, especially during the summer period, providing an alternative source of income for the locals. However, many houses are owned by people already living in larger cities or abroad with limited positive impact on the local economy.

Its urban form is self-contained, around an historical nucleus that is almost entirely abandoned, surrounded by relatively new housing developments (mostly underutilised second homes) and then by fields (Figure II.2.2).

\section{A Preparatory Decade (2008-2018)}

Like many other rural towns of southern Italy, Gagliato is a town in decline, still featuring a good quality of life, a mild hilly climate even during the hot Italian summer, and immersed in a typical rural Calabrian landscape, lying in the valley of the river Ancinale. While these have not yet become conditions to fight its decline, as numbers can witness, they have resulted in becoming a valuable asset for a group of international scholars. The unusual story of the Festival of Nanosciences started in 2008, when the first informal meeting was organised. ${ }^{2}$ Later on, in 2009, the Academy of Gagliato was founded to provide support for what will soon become an annual and increasingly famous international gathering in the field of nanosciences. The decade 2008-2018 was de facto a preparatory decade for the transdisciplinary experiment tested later on. According to the Academy of Gagliato members, the initiative was initially observed with curiosity by the local community but also seen with sceptical resistance. This is a trait that is not surprising, but would rather confirm attitudes and behaviours of relatively isolated communities, particularly in southern Italy, where a certain lack of trust and disengagement from public affairs have historically prevailed (Putnam, Leonardi, \& Nanetti, 1993). Nevertheless, the role of the Academy of Gagliato in the public life of the community has increased gradually with a series of tangible actions. First and foremost, the academy is a joint initiative of non-local members (international scholars) and those from Gagliato. The community of international scholars has also assumed a public profile since the very beginning, opening their debates to the community. The idea was to replicate, on a small scale, famous science festivals where people can participate and listen, and expert knowledge is translated for the general public. This 


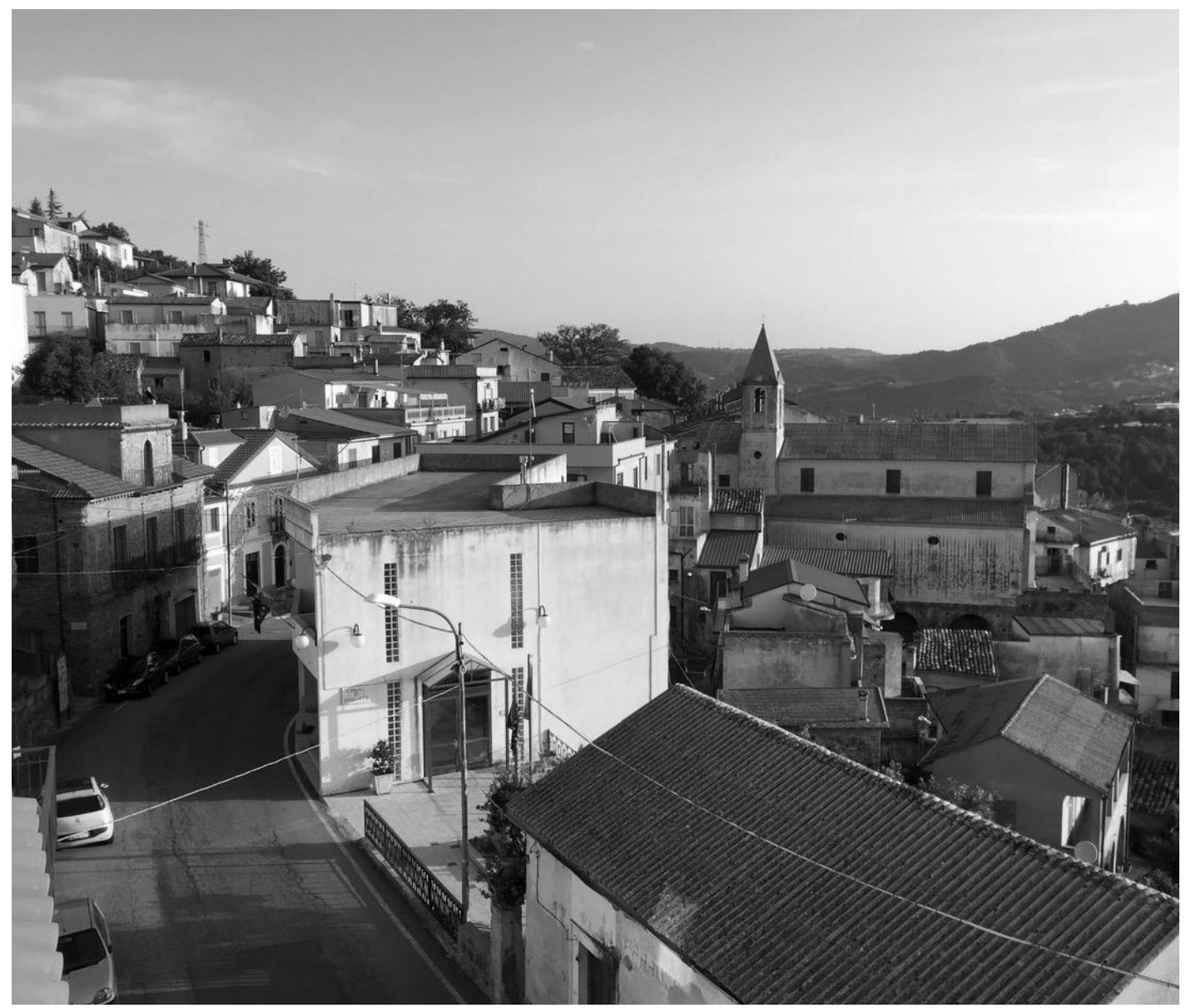

FIGURE II.2.2 A view of Gagliato with the church of Saint Nicola Vescovo. Photo by Giulio Verdini.

has materialised in the so-called "Serata in Piazza" (evening in the piazza), the concluding public event of the summer gathering, which has become an important appointment for the people of Gagliato and beyond. Moreover, a fundamental component of the Academy of Gagliato is the socalled "Nanopiccola," which aims to involve the children of Gagliato in various activities related to science, technology, engineering and mathematics learning, both during the summer event and over the year. It is an initiative that has helped to engage various local families in the life of the academy.

The process described here was a catalyst to build trust among the local community. The turning point was the election of 2015, when a political party formed by a group of young local professionals won the election with a large majority. In 2014, they formed a "civic alliance" (lista civica) named "Gagliato in Comune," campaigning for the valorisation of Gagliato and including the Academy of Gagliato as one of its main assets. The electoral programme contained projects and initiatives to improve the quality of life of the town and to boost economic development. The idea of supporting "scientific tourism" was given priority, due to the potential positive impact of the summer festival and possibly the organisation of a series of correlated initiatives over the year. While the seasonality 
of the science festival still remains an issue to be overcome, this joint effort between the municipality and the Academy of Gagliato has achieved some results. New retail activities have been set up, a bed and breakfast was opened and some new projects have started, including the restoration of an old oil mill located in the town, which should become the headquarters of the Academy of Gagliato.

Taken together, these tangible results have helped to raise the level of trust of the community, as they have challenged the inertia that is often so diffuse in such contexts (La Spina, 2008). It has to be clarified that, although this "dynamism" has led to some small tangible results, it is still far from being considered a structural process of local development. As a matter of fact, the growth generated is still volatile, pretty much entirely depending on exogenous activities and poorly rooted in the enhancement of local/territorial capacities (Trigilia, 2005). Still, the Academy of Gagliato has gradually contributed to generating a positive "atmosphere for change." It would otherwise be difficult to explain why the municipality and its leader have so firmly welcomed the idea of a civic engagement experiment in the town and, more concretely, why an estimated amount of almost $10-15 \%$ of citizens decided to gather on a hot, sunny Sunday morning in July 2017 to discuss their future development with a group of academics.

\section{The Participatory Design Workshop: Process and Outcomes}

As already mentioned, Gagliato was included in the 2016 United Nations Educational, Scientific and Cultural Organization report "Culture: Urban future" as an example of how culture can contribute to rural development, given the presence of the science festival and the related educational activities (Verdini, 2016). This stimulated great local attention, resulting in the organisation of a seminar in Calabria on "Small town, urban spaces and reimagined communities" in July 2016. In that context, members of the local authority, with representatives from the Academy of Gagliato and academics, discussed ways to reimagine the future of Gagliato, setting up a preliminary agenda of cooperation. The role of the Academy of Gagliato was very proactive as they envisioned, within the context of such cooperation, ways to further integrate their educational mission into the local life of the community, enhancing their impact for more sustainable patterns of development.

When the proposal of hosting a participatory design workshop in situ was made, they welcomed the idea very much. Regular discussions took place between 2016 and 2017 and a preparatory field visit was organised in May 2017. The proposal was widely debated in the town hall from the beginning, and this helped to engage the community and generate interest.

Scholars and students were selected to ensure a balanced mix of disciplinary backgrounds, particularly from architecture, urban planning and local economic development. Five broad topics were selected and agreed with local stakeholders, as reported in Table 5.1: the town of nanotech; the town of kids; the town of wellbeing; the town of skills and creativity; the town of science and art.

These different scenarios were selected for their current and potential relevance in the future development of the town, envisioning for each of them a potential pool of actors to be involved, and various dimensions of sustainability to be taken into account: territorial/governance; economic; ethical/social; tools; and risks/threats (including environmental ones).

The participatory activity took place by the end of July 2017. A historic palace located in the centre of town was made available to students and opened to citizens during the focus group activity. Each group prepared material for interaction with the local community including maps, posters, models and so on (Figure II.2.3). 


\begin{tabular}{|c|c|c|c|c|c|c|c|c|}
\hline & \multirow{2}{*}{$\begin{array}{l}\text { Visions / } \\
\text { Futures }\end{array}$} & \multirow[t]{2}{*}{ Topics } & \multirow[t]{2}{*}{ Engagement } & \multicolumn{5}{|l|}{ Dimensions } \\
\hline & & & & $\begin{array}{l}\text { Territorial / } \\
\text { Governance }\end{array}$ & Economic & $\begin{array}{l}\text { Ethical / } \\
\text { Social }\end{array}$ & Tools & $\begin{array}{l}\text { Risks / } \\
\text { threats }\end{array}$ \\
\hline A & $\begin{array}{l}\text { The } \\
\text { Town of } \\
\text { Nanotech }\end{array}$ & $\begin{array}{l}\text { NaoBorgo } \\
\text { regeneration; } \\
\text { smart village, } \\
\text { insiders/ } \\
\text { outsiders }\end{array}$ & $\begin{array}{l}\text { Citizens; } \\
\text { Academy } \\
\text { of Gagliato } \\
\text { stakeholders }\end{array}$ & Gagliato & $\begin{array}{l}\text { Cultural } \\
\text { and event } \\
\text { economics }\end{array}$ & $\begin{array}{l}\text { Knowledge } \\
\text { spreading, } \\
\text { nurturing } \\
\text { science }\end{array}$ & $\begin{array}{l}\text { Master Plan, } \\
\text { strategic } \\
\text { visioning }\end{array}$ & Temporariness \\
\hline B & $\begin{array}{l}\text { The Town } \\
\text { of kids }\end{array}$ & $\begin{array}{l}\text { Creative } \\
\text { Public space; } \\
\text { education: } \\
\text { schools and } \\
\text { informal } \\
\text { STEM } \\
\text { learning } \\
\text { walkability }\end{array}$ & $\begin{array}{l}\text { Nanopiccola } \\
\text { (Kids) }\end{array}$ & $\begin{array}{l}\text { Gagliato and } \\
\text { surrounding } \\
\text { municipalities }\end{array}$ & $\begin{array}{l}\text { Investing } \\
\text { in future } \\
\text { generations }\end{array}$ & $\begin{array}{l}\text { Nurturing } \\
\text { and inspir- } \\
\text { ing young } \\
\text { generations, } \\
\text { giving voice } \\
\text { to vulnerat- } \\
\text { ble groups }\end{array}$ & $\begin{array}{l}\text { Guidelines, } \\
\text { pilot project }\end{array}$ & Brain drain \\
\hline $\mathrm{C}$ & $\begin{array}{l}\text { The } \\
\text { Town of } \\
\text { Wellbeing }\end{array}$ & $\begin{array}{l}\text { Public Health, } \\
\text { elderly, } \\
\text { environmental } \\
\text { friendly town, } \\
\text { community- } \\
\text { based health } \\
\text { care }\end{array}$ & $\begin{array}{l}\text { Citizens; } \\
\text { general } \\
\text { practitioner; } \\
\text { pharmacist; } \\
\text { nanogagliato } \\
\text { public health } \\
\text { scholars }\end{array}$ & $\begin{array}{l}\text { Gagliato and } \\
\text { its municipal } \\
\text { territory }\end{array}$ & $\begin{array}{l}\text { Health } \\
\text { economics }\end{array}$ & $\begin{array}{l}\text { Solidar- } \\
\text { ity, healthy, } \\
\text { society, } \\
\text { reciprocity }\end{array}$ & $\begin{array}{l}\text { Guidelines, } \\
\text { pilot projects }\end{array}$ & $\begin{array}{l}\text { Pollution, } \\
\text { environmental } \\
\text { damages, lack } \\
\text { of prevention }\end{array}$ \\
\hline $\mathrm{D}$ & $\begin{array}{l}\text { The } \\
\text { Town of } \\
\text { Skills and } \\
\text { Creativity }\end{array}$ & $\begin{array}{l}\text { Creative } \\
\text { industry, rural } \\
\text { development, } \\
\text { tourism, local } \\
\text { and migrants }\end{array}$ & $\begin{array}{l}\text { Industry and } \\
\text { SMEs; local } \\
\text { authority }\end{array}$ & $\begin{array}{l}\text { Gagliato } \\
\text { and the } \\
\text { municipalities } \\
\text { of 'Vale } \\
\text { dell'Ancinale' }\end{array}$ & $\begin{array}{l}\text { Local } \\
\text { development, } \\
\text { balanced } \\
\text { regional } \\
\text { economics }\end{array}$ & $\begin{array}{l}\text { Innovation, } \\
\text { social } \\
\text { inclusion }\end{array}$ & $\begin{array}{l}\text { Local } \\
\text { development } \\
\text { plan, strategic } \\
\text { visioning }\end{array}$ & $\begin{array}{l}\text { Lack of } \\
\text { Infrastructure, } \\
\text { corruption }\end{array}$ \\
\hline E & $\begin{array}{l}\text { The Town } \\
\text { of Science } \\
\text { and Art }\end{array}$ & $\begin{array}{l}\text { Noanoborgo } \\
\text { regeneration; } \\
\text { public art and } \\
\text { open science }\end{array}$ & $\begin{array}{l}\text { Citizens; } \\
\text { academy of } \\
\text { Gagliato } \\
\text { stakeholders }\end{array}$ & $\begin{array}{l}\text { Gagliato and } \\
\text { its municipal } \\
\text { territory }\end{array}$ & $\begin{array}{l}\text { Cultural } \\
\text { and event } \\
\text { economics }\end{array}$ & $\begin{array}{l}\text { Knowledge } \\
\text { spreading, } \\
\text { nurturing } \\
\text { creativity }\end{array}$ & $\begin{array}{l}\text { Strategic } \\
\text { visioning, } \\
\text { pilot projects, } \\
\text { guidelines }\end{array}$ & Temporariness \\
\hline
\end{tabular}

TABLE II.2.1 Gagliato creative Towns workshop 2017. Living Lab: co-creation of knowledge and scenarios.

As the Academy of Gagliato and the group of international scholars in nanoscience were present for their annual gathering, an additional knowledge exchange meeting was organised to obtain their perspective on how they could better contribute to the future of the town.

At the end of the week, two public presentations were made in the town hall of Gagliato and in the auditorium of the Calabria regional authority. The two sessions were useful to obtain feedback and improve the proposal. Various documents and reports were later released (Verdini, Bina, \& Cioboata, 2018) including a follow-up report more focused on architectural propositions (Wills et al., current volume).

\section{Some Tangible Results and the Local Response}

Although it is not the goal of this chapter to enter into the details of the overall proposal, it is worth summarising its results, to see what has been taken on board by both the local community and the Academy of Gagliato. This can allow us to relate the transdisciplinary experience tested to 


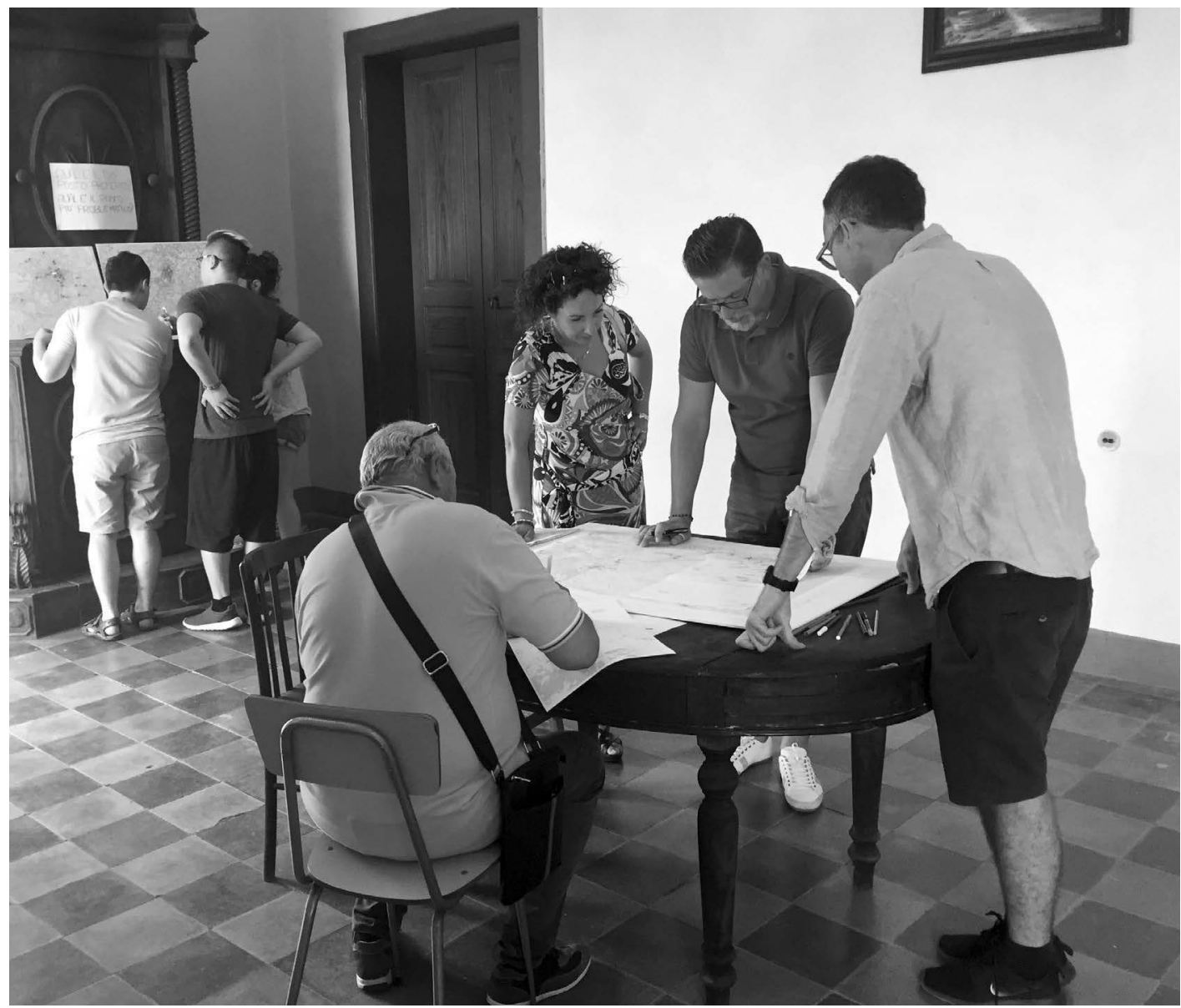

FIGURE II.2.3 The participatory design workshop: Local people discussing the future of Gagliato. Photo by Giulio Verdini.

the impact obtained on the ground. In the policy recommendations document produced after the workshop, the following points were raised:

1. To develop a series of initiatives in Gagliato and the Region of Calabria to explore how nanotech expertise can contribute to local wealth, mainly by looking at synergies between local agricultural productions and advanced research in nanotechnology (Group A).

2. To develop a landscape-based approach to urban regeneration, profiling local productive opportunities in the area (example: oregano) (Group A).

3. To develop pilot projects in the field of education by looking at both the innovation of curricula and the regeneration of the town's public space as a playground for children, in an attempt to relate a proposed science, technology, engineering and mathematics school to more practical and locally relevant skills (Group B).

4. To improve local wellbeing by developing synergies between food, landscapes, education and innovation in local cuisine (Group C). 
5. To improve local wellbeing by developing programmes to enhance the quality of the environment (asbestos being one of the priorities to tackle) (Groups C and E).

6. To start the urban regeneration of the main road as a panoramic balcony, setting up a series of linked events over the year (Group D).

7. To support art-based activities and events to revitalise the old (ghost) town, and improve the public space, such as squares, staircases and so on (Groups D and E).

8. To develop financial and legal mechanisms to incentivise the reallocation of vacant houses in the historic centre for a fixed time, subject to building regeneration and asbestos clearing (Group E). ${ }^{3}$

In July 2018, exactly one year after the organisation of the participatory workshop, a seminar was held to draft a balance and to appreciate some preliminary tangible results. These can be summarised in two main points: the preliminary exploration of synergies between nanotech expertise and local agricultural production, and the contribution of artists to the revitalisation of the old town.

The first point was surely one of the most debated. The proposal of using the annual gathering of experts as a catalyst for exploring synergies between their specific expertise in nanotechnology and activities that could matter directly to local people was considered most seriously by the Academy of Gagliato. It was a tangible proposal to improve the activities of the academy, often seen as too distant from the local community. It was the outcome of a conversation of focus group A with local agricultural entrepreneurs, which found further consensus locally. As a matter of fact, the academy has already started forms of cooperation with the local University of Catanzaro, where nanotech experiments have been conducted on agriculture. This could support, for example, the development of natural cosmetics from local produce such as oregano.

The other proposal of involving artists to improve the public space has been followed up by the Università Mediterranea di Reggio Calabria, and in summer 2018 the first public staircase of Gagliato was painted (Figure II.2.4).

In addition to this, funding applications have been submitted to ensure a more substantial economic and environmental regeneration process for the old town.

\section{Enablers and Barriers}

The enabling conditions and potential barriers to achieve meaningful transdisciplinary outcomes and consequently tangible positive urban transformation of the experience of Gagliato will be discussed in relationship to the various phases of the project. In particular, these are the co-design, co-production and continuation phases.

As argued from the start, it is evident that the co-design phase of the workshop in Gagliato was very smooth and positive from the very beginning. The process of agenda setting came very naturally after public discussions were held in Gagliato. The decade before the workshop gradually saw an increasing engagement of the local authority and citizens in the activities of the Academy of Gagliato. This was a process of building reciprocal trust and developing social capital locally. This is not far from the idea, already widely discussed within international agencies, that outside assistance can help in the process of social capital formation of places, and initiatives to support social capital can improve project effectiveness (World Bank, 1998). Therefore, when the Academy of Gagliato proposed an urban design workshop, the response was enthusiastic. At the same time, while the institutional and social context was favourable, the form of local government was also particularly effective. As a matter of fact, the new "civic alliance" that won the election in 2015 is constituted by a wide participatory base (called the "committee of 60," as almost 60 people take part regularly 


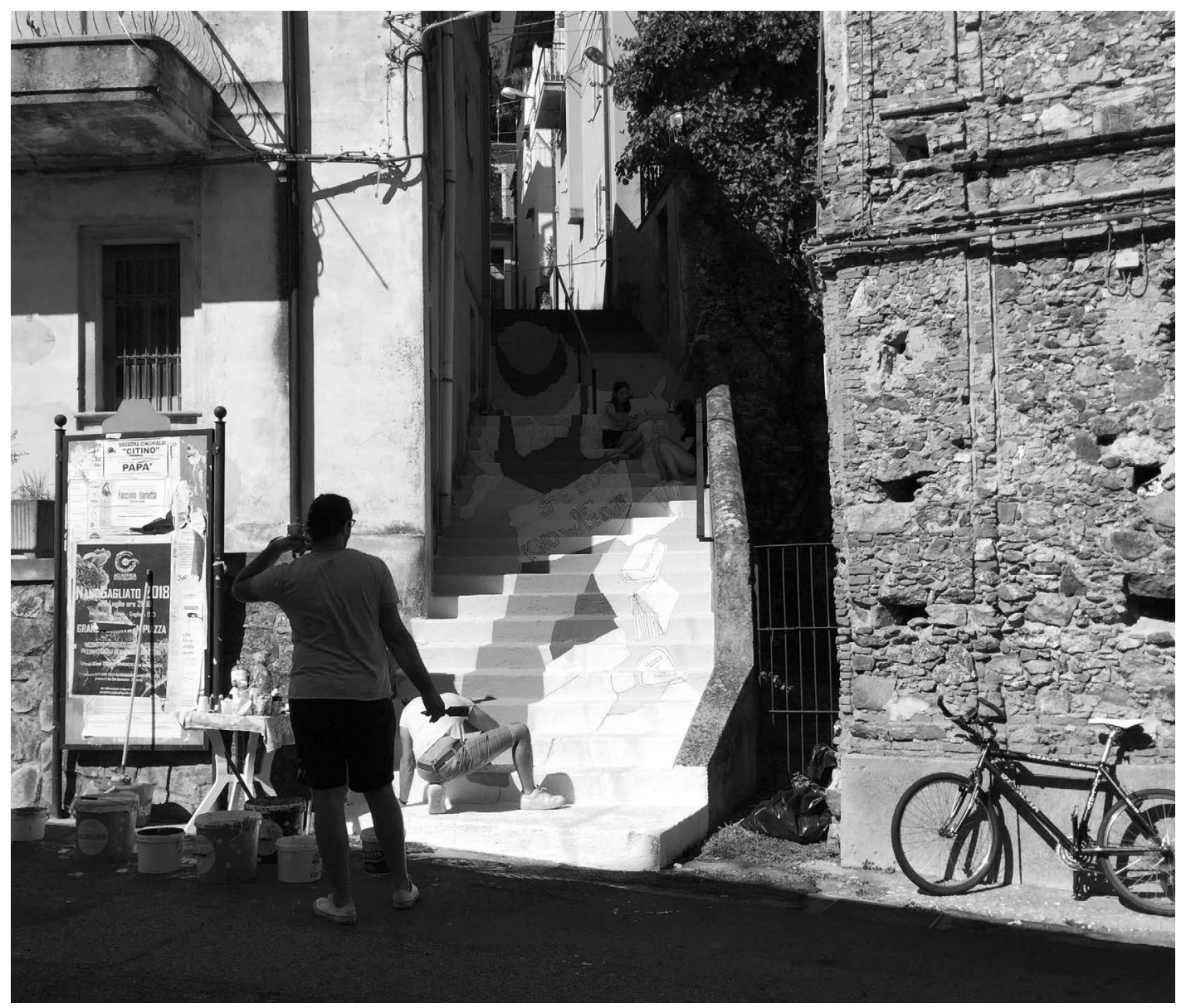

FIGURE II.2.4 The painting of one staircase of Gagliato during NanoGagliato 2018. Photo by Giulio Verdini.

in meetings), and the preparatory work was constantly shared during town hall committee meetings open to the community. This is a case of "empowered participatory governance," which relies on the commitment and capacities of ordinary people and ties action to discussion (Fung \& Wright, 2003), and it is ultimately an example of the specific design of institutions, which can or could deliver transformative democratic strategies (Watson, 2013).

The co-production phase was an exciting and partially unpredictable experience. Five interdisciplinary groups led by scholars based in various countries (Italy, Portugal, the United Kingdom, China and India) with a very international pool of students (from Italy, the United Kingdom, Germany, Norway, Egypt, Lebanon, Mexico and the United States) worked in focus groups or tables of discussion with Gagliato citizens and engaged in knowledge-sharing sessions with members of the Academy of Gagliato and their international guests. Each table had an Italian native speaker that could translate into English. According to the ex-post survey conducted among group leaders, the process was successful overall, although there were some weaknesses that could potentially emerge in the long run. In principle, the interactive, collaborative workshop is perceived as effective with the 
potential to build capacities and empower people. It was also an opportunity to collaborate among diverse, different cultures and academic/professional backgrounds, encouraging the participants to reflect on their roles. The benefits were various: the students had the opportunity to learn from realworld challenges and profit from the local community's experience, and the local community benefited from the participants' expertise and was empowered to become "agents of change" (Verdini, Bina, \& Cioboata, 2018). It was a way to materialise the recommendations of the United Nations Educational, Scientific and Cultural Organization agenda for "Education for sustainable development" (United Nations Educational, Scientific and Cultural Organization, 2017).

However, scholars within the co-production process have highlighted some limitations of it. In primis, it was difficult to find common languages and to overcome the problem of an unbalanced set of skills in each group, particularly given the limited time available, which is a typical interdisciplinary problem. More than that, despite the unanimous consensus on how enriching the interaction of the people was, some concerns were raised in the transdisciplinary process. These are related to: time constraints, a certain lack of skills when engaging with specific target groups (such as children) and, more seriously, the risk of raising expectations of the local community that could not be met, particularly when very concrete solutions to their real-life problems were implicitly required.

In this respect, no matter how smooth the process can be, which was quite unanimously acknowledged as positive (overall good management of the interactive process, and genuine exchange between scholars, students and people), the goal of the entire process may have been misunderstood. According to one scholar, the goal should be to provide ideas that policymakers need to translate into solutions, and not to provide abstract solutions that might look good on paper but are not feasible in practice.

This is linked particularly to the continuation of the process. The question on who should be realistically involved in delivering the proposals of the workshop is not easy to answer. There is an expectation that the academic partner will continue to support the process. This can be partially achieved (via remote support, mentoring, review and so on) but it obviously decreases when the funding comes to an end. It is not the case that the two proposals that have been implemented so far are those that could be more easily "owned" by local partners: the Academy of Gagliato itself, which is now promoting the application of nanotechnology to local produce; and the local Università Mediterrenea di Reggio Calabria, which is committed to working with students and artists on improving public space as part of their ordinary teaching activities.

The continuation of the project is a local matter and it will depend on how local stakeholders will utilise the material produced, and how much they will be able to mobilise further resources. It is promising that in October 2018 Gagliato applied for regional funding for urban regeneration using some of the ideas co-produced during the workshop. No matter what the result may be, these ideas will last for a long time and concrete opportunities may arise in the future. Given the presence of the Academy of Gagliato, it is likely that they will be committed to pursue this goal well beyond the end of the funding period of the research, which is understandably one of the major barriers of transdisciplinary research.

Nevertheless, the risk of dissipation of this experience is quite high if its dynamism does not turn into a more rooted development process, creating resilient and long-lasting opportunities and partnerships for development among local stakeholders. This resembles the conclusion that "transdisciplinary processes do produce different types of socially robust knowledge, but this does not necessarily result in the ability to influence change in a sustainable direction" (Polk, 2014). 


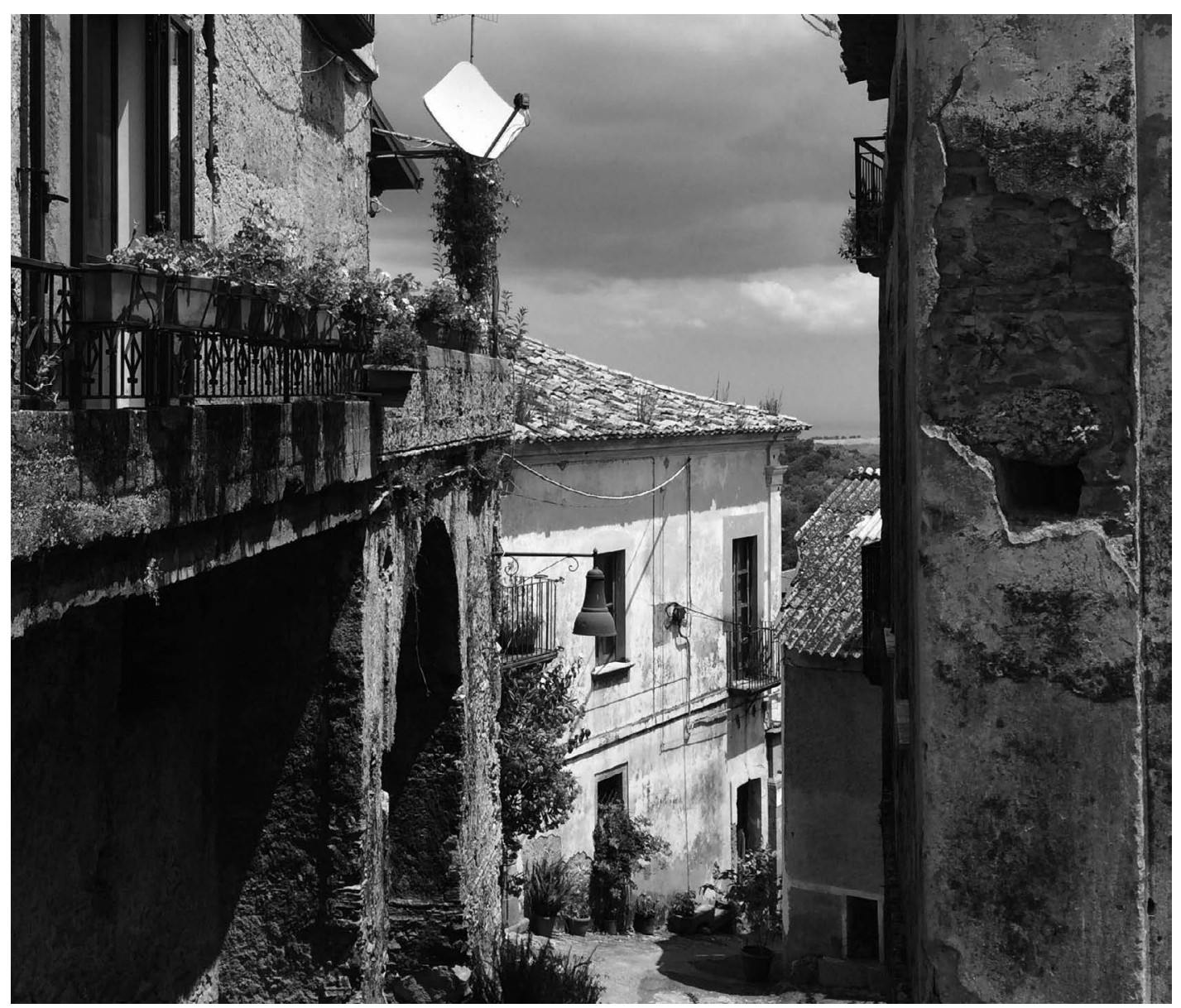

FIGURE II.2.5 Gagliato: semi-abandoned historic town centre. Photo by Giulio Verdini.

\section{Learning and Concluding Remarks}

The experience of Gagliato has been dense and rich for all the participants. After more than one year, we still receive emails from students who wish to participate again in similar experiences. Equally, the channel of communication with local people and the members of the Academy of Gagliato has never really stopped. This could be enough to draw some positive conclusions, at least from the (academic) perspective of the authors. The effort employed in organising such activity has been also huge and, as it emerges from this chapter, most of the successful results of the transdisciplinary experience depended on the "atmosphere of change," which was patiently developed over a relatively long period of time by people with great passion and determination (namely the members of the Academy of Gagliato). Yet, the question of whether such effort can produce sustainable change and real positive impact on people's lives is still unclear and remains open for discussion. It is probably too early to evaluate this, but nevertheless, it will be pretty much dependent on how the local context will react to the stimulus introduced during the workshop in the near future.

The Gagliato experience has helped to refine a working process and a set of competences, which 
are replicable and may be incorporated into university urban curricula. It is a desirable aspect, which is linked to the reflection of the open university (or the university we want) as put forward in the INTREPID London workshop in March 2017. What would be ultimately very valuable, in terms of teaching and learning innovation, is to learn how to pair inter- and transdisciplinary methods, skills and knowledge, with some learning coming from the Gagliato experience, particularly the dimension of ethical and collective action that took place in that context. As academics, a good result would be to train a new generation of skilled professionals in the urban field who could operate as inter-/transdisciplinary facilitators but could also act effectively as agents of change where they work in their respective contexts, no matter whether in Europe, China or India. If no impact is achieved locally in terms of sustainable development, there is still a high chance that learning for sustainable development will be applied elsewhere.

\section{Acknowledgements}

The research reported here was jointly funded by the Academy of Nanosciences of Gagliato and the EU COST ACTION INTREPID (TD1408). A special thanks goes to Paola Ferrari, Mauro Ferrari and Giovanni Sinopoli from the Academy and, it goes without saying, to the citizens of Gagliato, who generously accepted us into their community, even if just temporarily. The support of Alessandra Mossa and Andrea Porelli has been invaluable, alongside the kind help of the team of Paola Cannavò from Università della Calabria. Students from the University of Westminster, Newcastle University, the London School of Economics and Università Mediterranea di Reggio Calabria made the work possible. We are also grateful to Paolo Ceccarelli from ILAUD, the International Laboratory of Architecture and Urban Design and Franco Rossi from the Region of Calabria, who stimulated our thinking along the process, envisioning real action for political change.

This work is ad memoriam of Domenico Aspro, the vice-mayor of Gagliato, who wanted us there, and unexpectedly passed away a few weeks before the workshop.

\section{Notes}

1 The information here reported primarily comes from the chapter on Gagliato in the research report on 'Creative small settlements' (Ferrari, 2017).

2 In 2008, Gagliato hosted the first international meeting of scientists and biotech leaders, under the initiative of Mauro Ferrari, a pioneer in the field of nanotechnology applied to medicine.

3 Group A: Etra Connie Occhialini (group leader), with Martin Miranda Antelo, Erminia D'Alessandro, Luigi Terranova, Anne Kruse. Group B: Prue Chiles and Maria Pilar Guerrieri (group leaders), with Shantelle Edwards, Patricia Mijares Chavez, Luca Venuto, Emma Kingman. Group C: Alan Mace (group leader) with Lara Berton, Diana Tello-Medina, Giuseppe Palermo, Kareem Wellington. Group D: Christian Nolf and Anna Paola Pola (group leaders) with James Anderson, Julian Banister, Manuela Guzzo, Lam Pham. Group E: Paola Raffa (group leader) with Siri Arntzen, Nora El Gazar, Myriam Khoury, Alessia Santaromita.

\section{References}

Aagaard K., \& Siune, K. (2002). The design and delivery of inter- and pluri-disciplinary research. Aarhus, Denmark: The Danish Institute for Studies in Research and Research Policy. Retrieved 20 November 2018 from http://ps.au.dk/fileadmin/site_files/filer_forskningsanalyse/dokumenter/afsk/Rapporter/ Rapport_2002_7.pdf. 
Arendt, H. (1958). The Human Condition, University of Chicago Press, Chicago.

Bina, O, Verdini, G., Inch, A, Varanda, M., Guevara, M., \& Chiles, P. (2017). INTREPID futures initiative: Universities and knowledge for sustainable urban futures: as if inter and trans-disciplinarity mattered, 4th INTREPID Report, COST Action TD1408, 11 May. Retrieved 20 November 2018 from http:// intrepid-cost.ics.ulisboa.pt/intrepid-reports-and-policy-briefs/

De Carlo, G. (2013). L'Architettura della partecipazione. (Originally published in 1972 as "An architecture of participation”. Melbourne: Royal Australian Institutes of Architects). Macerata, Italy: Quodlibet.

Dyckhoff, T. (2017). The age of spectacles: Adventure in architecture and the 21st century city. London: Random House Books.

Elmqvist, T., Bai, X., Frantzeskaki, N., Griffith, C., Maddox, D., McPhearson, T., Parnell, S., RomeroLankao, P., Simon, D., \& Watkins, M. (2018). Urban planet: Knowledge towards sustainable cities. Cambridge: Cambridge University Press.

Ferrari, P. (2017). Gagliato, Calabria. In: Verdini, G., \& Ceccarelli, P. Creative small settlements: Culturebased solutions for local sustainable development, pp. 91-100. London; Suzhou, China: University of Westminster; Xi'an Jiaotong-Liverpool University.

Fung, A., \& Wright, E. (2003). Deepening democracy: Institutional innovations in empowered participatory governance. London: Verso.

La Spina, A. (2008). Ambitions and failures of some local development policies for the Mezzogiorno: Territorial agreements and integrated territorial programs. Quaderni di Sociologia, 48, 21-38.

Merrifield, A. (2014). The new urban question. London: Pluto Press.

Petts, J., Owens, S., \& Bulkeley, H. (2008). Crossing boundaries: Interdisciplinarity in the context of urban environments. Geoforum, 39, 593-601.

Polk, M. (2014). Achieving the promise of transdisciplinarity: A critical exploration of the relationship between transdisciplinary research and societal problem solving. Sustainability Science, 9, 439-451.

Putnam, R., Leonardi, R., \& Nanetti, R. (1993). Making democracy work: Civic traditions in modern Italy. Princeton, NJ: Princeton University Press.

Rowe, C., \& Koetter, F. (1978). The collage city. Cambridge, MA: The MIT Press.

Simon, D., Palmer, H., Riise, J., Smit, W., \& Valencia, S. (2018). The challenges of transdisciplinary knowledge production: From unilocal to comparative research. Environment and Urbanization, 30, 481-500.

Trigilia, C. (2005). Sviluppo locale. Un progetto per l'Italia. [English: Local Development. A project for Italy]. Bari, Italy: Editori Laterza.

United Nations Educational, Scientific and Cultural Organization. (2016). Culture: Urban future. Global report on culture for sustainable urban development. Paris: United Nations Educational, Scientific and Cultural Organization. Retrieved 20 November 2018 from http://unesdoc.unesco.org/ images/0024/002459/245999e.pdf.

United Nations Educational, Scientific and Cultural Organization. (2017). Education for sustainable development goals: Learning objectives. Paris: United Nations Educational, Scientific and Cultural Organization. Retrieved 20 November 2018 from http://unesdoc.unesco.org/images/0024/002474/247444e.pdf.

Verdini, G. (2016). Culture as a tool for harmonious territorial development. In: United Nations Educational, Scientific and Cultural Organization. Culture: Urban future. Global report on culture for sustainable urban development, pp. 212-219. Paris: United Nations Educational, Scientific and Cultural Organization. Retrieved 20 November 2018 from http://unesdoc.unesco.org/images/0024/002459/245999e.pdf.

Verdini, G., Bina, O., \& Cioboata, S. (2018). INTREPID futures initiative: The future of academia and transdisciplinary knowledge production in the urban field. 6th INTREPID Report, COST Action TD1408, 8 January. Retrieved 20 November 2018 from http://intrepid-cost.ics.ulisboa.pt/intrepid-reports-andpolicy-briefs/

Verdini, G., \& Ceccarelli, P. (2017), Creative small settlements: Culture-based solutions for local sustainable development. London; Suzhou, China: University of Westminster; Xi'an Jiaotong-Liverpool University. Retrieved 20 November 2018 from http://www.intrepid-cost.eu/wp-content/uploads/2017/06/CreativeSmallSettlements.pdf. 
Watson, V. (2013). Co-production and collaboration in planning - the difference. Planning Theory and Practice, $15,62-76$.

World Bank. (1998). The initiative on defining, monitoring and measuring social capital: Overview and program description. Washington, DC: World Bank.

World Social Science. (2014). Transformations to sustainability in urban contexts - concept note. 2nd World Social Science Fellows seminar on Sustainable Urbanization, Taipei. Retrieved 20 November 2018 from http://www.worldsocialscience.org/documents/concept-note-sustainable-urbanization-ii-taiwan.pdf. 